\title{
Implications of diverse sulfur oxidizing microbes on sulfur cycling in circumneutral mining wastewaters
}

LAUREN E. TWIBLE1, JAMES ARREY1, Kelly WhaleyMARTIN1, TARA NELSON COLENBRANDER1, \& LESLEY A. WARREN $1^{*}$

1Department of Civil and Mineral Engineering, University of Toronto, Toronto, Ontario, Canada (*correspondence:

lesley.warren@utoronto.ca)

Sulfur oxidation intermediates (SOIs) generated through mineral processing on mine sites can have significant environmental implications such as contaminant mobilization, oxygen consumption and acid generation (i.e. acid mine drainage (AMD)) if they reach receiving environments. Tailings ponds are often circum-neutral and the microbial communities involved in circum-neutral sulfur cycling are still poorly characterized. The objective of this experiment was to identify sulfur oxidizing bacteria (SoxBac) grown on mixed SOI media ( $\mathrm{S}_{2} \mathrm{O}_{32-}, \mathrm{S}_{4} \mathrm{O}_{62}-, \mathrm{S}_{0}$ and $\left.\mathrm{SO}_{32-}\right)$ at two [SOI] (approximately field concentration and 10x field concentration) and assess their impacts on sulfur cycling and acid production for wastewaters collected in June 2018. These waters were collected from parent tailings ponds as well as their receiving environments of four mines across Canada. For each of the 16 treatment ( 4 mine $\times 2$ site types $\times 2$ [SOI]) enrichment experiments, $\mathrm{pH}$ was kept circumneutral ( $\mathrm{pH} 7-5)$ and samples were collected and analyzed for 16S rRNA sequencing and SOI speciation for $\mathrm{t}=0$ and $\mathrm{t}=\mathrm{end}$ of the third SoxBac generation.

While all SoxBac enrichments were dominated by Gammaproteobacteria, the most abundant SoxBac genera included Halothiobacillus spp., Thiobacillus spp. and Sulfuriferula spp. that showed highly divergent representation across samples. Results show that SoxBac enrichment community structure did not cluster by individual mine, sample type or enrichment treatment conditions and reflected a shift between Sulfuriferula spp. - Thiobacillus spp. and Halothiobacillus spp. dominance.

Associated sulfate and acid production, a proxy of greater oxidation rather than sulfur recycling and SOI disproportionation reactions, was highest for Halothiobacillus spp. dominated SoxBac consortia compared to Sulfuriferula spp. - Thiobacillus spp. SoxBac enrichments irrespective of enrichment experiment [SOI].

These results clearly identify the importance of SoxBac ecology in determining overall sulfur cycling and water quality implications for mining wastewaters. 